\title{
Sport and Leisure-time Physical Activity at Patients with Cardiomyopathy
}

\author{
Marko Mornar Jelavićc ${ }^{1,2}$ (D) , Zdravko Babicí ${ }^{3,4,5}$, Hrvoje Pintaricic, \\ ${ }^{1}$ Institute for Cardiovascular Prevention and Rehabilitation, Zagreb, Croatia \\ ${ }^{2}$ School of Dental Medicine, University of Zagreb, Zagreb, Croatia \\ ${ }^{3}$ School of Medicine, University of Zagreb, Zagreb, Croatia \\ ${ }^{4}$ Faculty of Kinesiology, University of Zagreb, Zagreb, Croatia \\ Coronary care unit, Department of Cardiology, Internal Medicine Clinic, Sestre milosrdnice \\ ${ }^{5}$ University Hospital Center, Zagreb, Croatia \\ ${ }^{6}$ Department of Emergency Medicine, Internal Medicine Clinic, Sestre milosrdnice University \\ Hospital Center, Zagreb, Croatia
}

OPEN ACCESS

Correspondence: Marko Mornar Jelavic, MD, PhD mjelavic@yahoo.com orcid.orcid.org/0000-0002-9135-1820

This article was submitted to RAD CASA- Medical Sciences as the review article

Conflict of Interest Statement: The authors declare that the research was conducted in the absence of any was concrial or financia com could be construed as a potentia conflict of interest.

Received: 6 June 2019 Accepted: 24 June 2019 Published: 22 July 2019

Citation

Mornar Jelavic and Pintaric. Aorti Stenosis From the Perspective of the Current Guidelines.

RAD CASA: Medical Sciences.

$543=50-51(2020): 29-36$ DOI: https://dx.doi.org/10.21857/ y6zolbrgkm

Copyright (C) 2019 Mornar Jelavic and Pintaric. This is an open-access article distributed under the terms arthe Creative Commons Attribution of the Creative Commons Attribution License (CC BY). The use, distribution or reproduction in other forums is permitted, provided the original author(s) and the copyright owners(s) are credited and that the original publication in this journal is cited, in accordance

whit accepted adacemic practice. No

use, distribution or reproduction is permitted which does not comply with
ABSTRACT:

Cardiomyopathy (hypertrophic, dilated, left ventricular non-compaction and arrhythmogenic cardiomyopathy) is primarily a genetic disease associated with an increased risk of potentially fatal cardiac arrhythmias and sudden death/cardiac arrest during exercise.

The diagnosis of cardiomyopathy is based on complete cardiac evaluation with detailed personal and family history, 12-lead ECG, echocardiogram, cardiac magnetic resonance imaging (CMRI), stress-testing, genetic testing and counseling. The differentiation between the physiological adaptation to exercise and cardiomyopathy is of the mutual importance.

In this review, we outline the latest recommendations published by the Sport Cardiology Section of the European Association of Preventive Cardiology (EAPC) on sport and leisure-time physical activity in patients with cardiomyopathy. It offers recommendations for practicing cardiologists and sport physicians managing athletes with cardiomyopathies and provides advice for safe participation in competitive sport at professional and amateur level, as well as in a leisure-time physical activity.

KEYWORDS: cardiomyopathy, athletes, competitive sport, leisure-time physical activity.

\section{SAŽETAK:}

SPORT I SLOBODNO VRIJEME U BOLESNIKA S KARDIOMIOPATIJOM

Kardiomiopatija (hipertrofijska, dilatacijska, hipertrabekulirana lijeva klijetka, aritmogena kardiomiopatija) je primarno genetska bolest povezana s povećanim rizikom potencijalno fatalnih kardijalnih aritmija i iznenadnom smrću/kardijalnim arestom tijekom vježbanja.

Dijagnoza kardiomiopatije bazirana je na kompletnoj kardiološkoj obradi s detaljnom osobnom i obiteljskom anamnezom, učinjenim elektrokardiogramom, ultrazvukom srca, magnetskom rezonancijom srca, stres testiranjem, genetskim testiranjem i savjetovanjem. Razlikovanje fiziološke prilagodbe srca na vježbanje od kardiomiopatije je od neobične važnosti.

U ovom pregledu donosimo najnovije preporuke Sekcije za sportsku kardiologiju pri Europskom drušvu za preventivnu kardiologiju (engl. EAPC) o sportskoj i rekreativnoj fizičkoj aktivnosti u bolesnika s kardiomiopatijom. Ona sadrži preporuke za kardiologe i sportske liječnike koji se bave sportašima s kardiomiopatijama i donosi savjete o sigurnom participiranju u kompetitivnom sportu na profesionalnoj i amaterskoj razini, kao i kod rekreativne fizičke aktivnosti.

KLJUČNE RIJEČI: kardiomiopatija, sportaši, kompetitivni sport, rekreativna fizička aktivnost. 


\section{INTRODUCTION}

In this review article, we outline the latest recommendations published by the Sport Cardiology Section of the European Association of Preventive Cardiology (EAPC) on sport and leisure-time physical activity in patients with cardiomyopathy. ${ }^{1}$ Cardiomyopathy is primarily a genetic disease recognized as a cause of exercise-related sudden cardiac death/cardiac arrest (SCD/CA) in athletes. The diagnosis of cardiomyopathy is based on complete cardiac evaluation with detailed personal and family history, 12-lead ECG, echocardiogram, cardiac magnetic resonance imaging (CMRI), stress-testing as well as genetic testing and counseling at some patients. The differentiation between the physiological adaptation to exercise and cardiomyopathy is of the mutual importance. The presence of cardiac symptoms and family history of cardiomyopathy are important red flags for pathology. The current document outlines the pertinent electrical, structural and functional features, which facilitate the differentiation between physiological cardiac adaptation and cardiomyopathy in athletes.

Sports activities are classified according to the cardiovascular changes associated with the exercise training and the long-term impact on cardiac morphology, as follows:

- Skill sport (golf, sailing, car/motor racing, table tennis, shooting, equestrian, archery, curling, scuba diving) includes athlete's neuromuscular coordination and skill (i.e. low dynamic, low static). It increases heart rate, which may be substantial, and only modest blood pressure and cardiac output. The longterm cardiac adaptation is minimal or no morphologic cardiac remodelling;

- Power sport (weightlifting, wrestling, shot-putting, bobsleigh, alpine skiing, snowboarding, sprinting, water skiing, rock climbing) includes explosive muscle power (i.e. high-static exercise). It increases blood pressure and heart rate for several, short repetitive bursts. The long-term cardiac adaptation is increase in LV wall thickness and modest change in LV cavity size; - Mixed sport (soccer, basketball, volleyball, football, rugby, waterpolo, handball, hockey, tennis, fencing, cricket) is based on the alternate phases of work (either dynamic and/or static) and recovery periods. It increases heart rate and blood pressure, while the long-term cardiac adaptation is an increase in LV cavity size and modest change in LV wall thickness; and

- Endurance sports (cycling, rowing, canoeing, triathlon, pentathlon, cross-country skiing, mid-long swimming, running and skaring) is based on prolonged and intensive dynamic exercise (i.e. high-dynamic, often associated with high-static exercise), with very high cardiac output, through persistent increase in heart rate and blood pressure. The long-term cardiac adaptation is increased LV cavity size and wall thickness.

\section{HYPERTROPHYC CARDIOMYOPATHY}

Hypertrophic cardiomyopathy (HCM) is primarily a genetic disease caused by mutations within genes encoding sarcomeric contractile proteins and one of the most common causes of exercise-related sudden cardiac death/cardiac arrest (SCD/CA) in athletes. ${ }^{3-5}$ It is characterized by a hypertrophied left ventricle (LV) not related to cardiac or systemic disease (ie. aortic stenosis, arterial hypertension) capable of inducing the same magnitude of LV hypertrophy. ${ }^{6,7}$

\section{Diagnostic evaluation}

The most of subjects are asymtpomatic with an abnormal 12lead ECG (large QRS voltages, T-wave inversions, ST-segment depression, pathological Q-waves), while the other may have a normal ECG and present with angina, syncope, or palpitation. ${ }^{8-10}$

Echocardiographic changes may include unexplained LV hypertrophy with maximum end-diastolic wall thickness $\geq 16 \mathrm{~mm}$ in any segment.6,7 Other individuals with LV wall thickness of 13-16 mm, another family member with HCM, positive genetic testing, or repolarization anomalies, may also have HCM. ${ }^{2,6,7}$ The most frequent is an asymmetric pattern of LV hypertrophy, with normal or reduced LV end-diastolic cavity size, while onethird of athletics had the apical variant. ${ }^{2,6,7,8,9}$ Normal athletes with physiological LV hypertrophy show a more homogeneous and symmetric distribution of wall thickness and an enlarged cavity (i.e. LV end-diastolic diameter $>54 \mathrm{~mm}$ ). ${ }^{11,12}$ Tissue Doppler Imaging (TDI) abnormalities may be present in the early stage of the disease, with the septal $\mathrm{E}^{\prime}<12 \mathrm{~cm} / \mathrm{s}$ and lateral $\mathrm{E}^{\prime}<12 \mathrm{~cm} / \mathrm{s}$ as the best diastolic markers for HCM.2,9,12,13 Strain assesment may be used for the detection of mycocardial contraction disturbances. ${ }^{2}$ Serial echocardiographic studies demonstrating regression of LV hypertrophy after a 3-month period of complete deconditioning in an athlete without family history of HCM are consistent with diagnosis of physiological LV hypertrophy. ${ }^{14}$

CMRI is recommended in all athletes with equivocal findings (LV wall thickness of 13-16 mm, electrical abnormalities, or symptoms suggestive of cardiac disease in the context of a family history of HCM) and in excluding localized hypertrophy of segments that cannot be visualized adequately with echocardiography (apex, antero-lateral segments). The presence of late gadolinium enhancement (LGE) is suggestive of myocardial fibrosis, and consistent with the diagnosis of HCM. ${ }^{15,16}$

Stress-testing with the presence of symptoms, non-sustained ventricular tachycardia (nsVT), ST-segment depression/T wave inversion, flat systolic blood pressure response (increase $<20$ $\mathrm{mmHg})$, and a low peak oxygen consumption $(<84 \%$ predicted $)$ suggest pathological LV hypertrophy. ${ }^{17}$

24-hour holter ECG with the occurrence of nsVT, or any complex ventricular arrhythmias in an athletic individual with a LV wall thickness 13-16 mm also favours the diagnosis of HCM. Genetic testing is currently recommended only in patients clearly fulfilling the diagnostic criteria for HCM, to enable cascade genetic screening of their relatives. ${ }^{6,18}$ 


\section{Recommendations}

Participation in high-intensity and highly dinamic competitive sports (ie. basketball, football, and swimming) has been considered as an independent risk factor for SCD/CA, due to accompanying alterations in hydration, electrolyte, and acid base status and surges in catecholamine levels. ${ }^{19}$ Participation should be considered on an individual basis, after full evaluation of the disease characteristics and risk determinants.

The major clinical features (parameters) which increases the risk of SCD/CA are age, family history of SCD/CA, unexplained syncope, LV outflow tract gradient (LVOT), maximum LV wall thickness, left atrial diameter, nsVT and abnormal blood pressure response to exercise. According to these parameters, patients are classified to low $(<4 \%)$, medium (4-6\%) and high $(>6 \%)$ 5-year risk. $^{6}$

- Sports participiation is absolutely contraindicated after aborted SCD/CA, symptoms (unheralded syncope), exercise-induced VT, high ESC 5-year risk score, significant increase in LVOT gradient $(>50 \mathrm{mmHg}$ ), and abnormal blood pressure response to exercise (Class IIb/Level C).

- Adult athletes with mild clinical expressions of HCM and low ESC risk score may selectively be allowed to participate in all competitive sports, with exception of those where occurrence of syncope may be associated with harm or death (Class IIb/Level C). Such athletes should be reviewed annually to assess symptoms and changes in risk profile.

- Genotype positive and phenotype negative (G+P-) individuals may be allowed to engage in all competitive sports (Class IIa/ Level C).

\section{DILATED CARDIOMYOPATHY}

Dilated cardiomyopathy (DCM) is a myocardial disease characterized by a dilated and hypokinetic LV or both ventricles. $20 \mathrm{It}$ may be primary (genetic) or secondary (infection, inflammation, toxic, ischaemic, idiopathic).

\subsection{Diagnostic evaluation}

The 12-lead ECG may be normal, similar to athletic training (atrial enlargement, axis deviation, large QRS voltages in the lateral leads), or may include T-wave inversions, intraventricular conduction defects (including LBBB), and $1^{\text {st }}$ degree atrioventricular (AV) block or pathological Q waves in the inferior and/ or lateral leads (lamin A/C or dystrophin mutations). Occurrence of ventricular arrhythmias, particularly during exercise, may be common. ${ }^{20}$

Echocardiography may reveal the LV cavity enlargement, with more spherical shape, and consequent mitral annulus dilatation, distortion of leaflets and resultant valvular regurgitation. Also, LV systolic function is reduced, the ejection fraction (LVEF) is usually below $50 \%$, and regional wall motion abnormalities are occasionally present.21,22 Elite athletes frequently demonstrate an enlarged LV cavity size.23 It should be interpreted in the context of the sporting discipline and body size (it is advised to relate LV cavity to body surface area) and is usually associated with increased wall thickness. ${ }^{2,23,24}$ The presence of concomitant RV remodelling, with normal RV function is consistent with a physiological LV remodelling.2 At athletes with an enlarged LV and mildly reduced LV ejection fraction (45-55\%) regional wall motion abnormalities and abnormal diastolic function may support DCM. ${ }^{25}$ Also, an increase in LV ejection fraction (>10-15\%) during exercise echocardiography or CMR supports the diagnosis of physiological LV dilatation. ${ }^{26,27}$

CMR is the gold standard for the assessment of biventricular dimensions and function in equivocal cases. Late gadolinium enhancement (LGE) identifies areas of replacement fibrosis and the presence of mid-wall LGE and its extent has emerged as an important tool in risk stratification of DCM..$^{28-30}$

Stress-testing may be inconclusive in the early stages of the disease, but the presence of a low peak oxygen consumption in an athlete with an enlarged LV and borderline/low LV ejection fraction supports DCM.

24-hour holter ECG may detect arrhythmias in approximately $30 \%$ of DCM patients, even in the presence of only mildly dilated LV cavity, which is important in risk stratification. ${ }^{30,31}$

\subsection{Recommendations}

Participation in intensive exercise programmes and competitive sport should be considered on an individual basis, after evaluation of the disease characteristics and risk determinants.

- The presence of LV cavity dilatation with preserved LV function, in the absence of a family history of DCM, abnormal ECG patterns, and atrial/ventricular tachyarrhythmias should be considered to represent expression of physiological cardiac remodelling rather than DCM. No restriction to competitive sports is applicable to this cohort of athletes (Class IIa, Level B).

- Sports participation is absolutely contraindicated at athletes with a diagnosis of DCM who are symptomatic, or have LV ejection fraction $<40 \%$, or extensive LGE (i.e. $>20 \%$ ) on CMR and/or frequent/complex ventricular tachyarrhythmias on 24-holter ECG and stress-testing, or history of unexplained syncope. These patients should be advised to limit their exercise programmes to leisure-time activities and undergo regular clinical surveillance, consistent with current recommendations for the management of DCM (Class III, Level C).

- Athletes with an unequivocal diagnosis of DCM, but mildly reduced LV systolic function ( $\mathrm{EF} \geq 40 \%)$ may selectively engage in all competitive sport (with the exception of those where occurrence of syncope may be associated with serious harm or death), if they are asymptomatic, without prior history of unexplained syncope, and without frequent/complex ventricular tachyarrhythmias on 24-hour holter ECG and stress-testing (Class IIb, Level C).

- Irrespective of the severity of LV dysfunction and dilatation, patients with a family history of SCD/CA and/or those 
previously identified during cascade screening for familial DCM, with mutations that are associated with an increased risk of life-threatening arrhythmias (such as Lamin A/C or Filamin C mutation), should not participate in competitive sports (Class IIb, Level C).

- In the absence of evidence for DCM, the G+P-individuals may be allowed to engage in all competitive sports, with the recommendation to undergo a periodical evaluation, at least annually, in order to early detect the phenotypic expression of the disease (Class IIa, Level C).

\section{LEFT VENTRICULAR NON-COMPACTION CARDIOMYOP- ATHY}

Left ventricular non-compaction (LVNC) is a genetic disease characterized by prominent trabeculations within the LV myocardium, separated by deep recesses, and usually associated with LV dysfunction and ventricular tachyarrhythmias.32 At athletes, it is diagnosed by the identification of a prominent trabecular pattern by cardiac imaging. ${ }^{2}$

\subsection{Daignostic evaluation}

At 12-lead ECG abnormalities include T-wave inversion, ST-segment depression and intraventricular conduction delay (ie. LBBB). ${ }^{33}$

Echocardiography and CMR reveal the presence of a two-layered structure of the myocardial LV wall, with increased non-compacted to compacted LV layer ratio ( $>2$ and $>2.3$ for echocardiography and CMR, respectively). $2,3,4,5,34,35$ Additionaly, we can find LV systolic dysfunction (with $\mathrm{LVEF}<50 \%$ ) and abnormal myocardial relaxation $(\mathrm{e} \mathbb{Q}<9 \mathrm{~cm} / \mathrm{s}$ at TDI).36 Increased cardiac preload may simply unmask pre-existing trabeculations and make them more prominent. Thus, athletes frequently show increased trabeculations in the LV cavity, and up to $8 \%$ may fulfil the morphological criteria for LVNC.36 But, only minority of them $(0.9 \%)$ exhibit other clinical abnormalities supportive for diagnosis of a cardiomyopathy (abnomal 12-lead ECG, mildly reduced LVEF, family anamnesis); these athletes need to be thoroughly investigated through CMR, exercise echocardiography and 24-hour holter ECG. ${ }^{2,36-38}$

\subsection{Recommendations}

The clinical outcome of LVNC is variable, related to the magnitude of LV dysfunction and ventricular arrhythmiass. Adverse consequences are largely associated with the severity of hypertrabeculations, LV systolic dysfunction or major ventricular tachyarrhythmias.36,38-41

- Athletes with incidental discovery of LV hypertrabeculation should not be diagnosed as LVNC in the absence of symptoms, positive family history, abnormal ECG patterns and, most importantly, impaired LV function. In such cases, no restriction for all competitive sports apply (Class IIa/Level B).

- Athletes with unequivocal/reasonable diagnosis of LVNC but near-normal LV systolic function may participate in all competitive sports (with the exception of those where occurrence of syncope may cause serious harm or death), if they are asymptomatic, without frequent and/or complex ventricular arrhythmias, or nsVT on 24-hour ECG and exercise stress-testing, and no prior history of unexplained syncope (Class IIb, Level C).

- Athletes with an unequivocal diagnosis of LVNC and impaired LV systolic function and/or frequent and/or complex ventricular arrhythmias, or nsVT on ambulatory monitoring or exercise stress-testing should not participate in competitive sports (Class III, Level C). These patients should be advised to limit their exercise programmes to leisure-time physical activities and remain under regular clinical surveillance.

\section{ARRHYTHMOGENIC RIGHT VENTRICULAR CARDIOMY- OPATHY}

Arrhythmogenic right ventricular cardiomyopathy (ARVC) is caused predominantly by mutations in genes encoding desmosomal proteins. It is characterized by fibro-fatty replacement of the right ventricle and/or LV myocardium, and clinically by life-threatening ventricular tachyarrhythmias triggered by exercise. ${ }^{42-44}$

\section{Diagnostic evaluation}

The 12-lead ECG is mostly abnormal.45 In the right-dominant variant, the most common abnormalities (leads V1-V3) are inverted T-waves, prolonged QRS duration $>110 \mathrm{~ms}$ with right bundle branch block (RBBB) pattern and a delayed upstroke (>55 ms) of the $S$ wave, an epsilon wave, and premature ventricular beats (PVBs) with LBBB pattern (vertical/horizontal axis). In the left-dominant variant, the most common abnormalities are low voltages of $\mathrm{R} / \mathrm{S}$ wave in the limb leads, the presence of diffuse T-wave inversion in the antero-lateral and inferior leads, and PVBs with RBBB pattern (superior axis). ${ }^{42,45}$

Echocardiography and CMR may show an enlarged RV and/ or LV cavity and wall motion abnormalities, which are evident only in advanced stage of the disease. ${ }^{2,46}$ It is important to emphasize that CMR has superior diagnostic value in identifying segmental morphological abnormalities, consistent with fibro-fatty replacement, including regional wall motion anomalies. ${ }^{2,42,47}$

As we already mentioned, endurance athletes develop an enlarged RV and LV cavities, both with preserved shape and the absence of segmental thinning or wall motion abnormalities, as consequence of the physiological adaptation to chronic exercise training. ${ }^{2,48,49}$ So, pathological RV remodelling needs to be associated with wall motion abnormalities to suggest ARVC. 50 Exercise echocardiography/CMR may be useful for discriminating between physiological RV enlargement from pathological RV myocardial remodelling, ie. an increase in LV ejection fraction (>10-15\%) during exercise echocardiography or CMR 
supports the diagnosis of physiological LV dilatation. ${ }^{26,27}$ During stress-testing and 24-hour holter ECG, exercise performance may be preserved. However, ventricular arrhythmias are usually present at an early stage of the disease, and are usually triggered by exercise.

\section{Recommendations}

The dilation of the right ventricle associated with regular exercise training may lead to myocardial damage and subsequent fibro-fatty replacement, thereby triggering the morphological features of the disease. Ventricular tachyarrhythmias and sudden death in ARVC commonly occur in association with exertion and ARVC accounts for a substantial proportion of deaths in young athletes. ${ }^{42,51}$ These considerations are clinically relevant and support a restrictive advice regarding the participation in intensive exercise programmes and competitive sports in affected ARVC patients. Conversely, recreational exercise programme conveys a reduced risk, such as that of patients physically inactive.

- Athletes with unequivocal or probable diagnosis of ARVC should not participate in competitive sports. These patients should be advised to limit their exercise programmes to leisure-time activities, and remain under clinical surveillance (Class IIa/Level C).

- Athletes who are genetic carriers of pathogenic ARVC -associated desmosomal mutations (even in the absence of phenotypic expression of the disease) should not participate in competitive sports. These athletes should be advised to limit their exercise programmes to leisure-time activities and remain under clinical surveillance (Class IIa/Level C).

\section{ATHLETES WITH CARDIOMYOPATHY AND IMPLANTED ICD}

The indications for an ICD in competitive athletes should not differ from the general population with a diagnosis of cardiomyopathy. Specifically, the desire of the athlete with cardiomyopathy to compete should not constitute a primary (or unique) indication for ICD implantation (Class IIa/Level C).

Recommendation for sports participations in an individual with an ICD should be based on the fact that the arrhythmogenic substrate of the cardiomyopathy remains unaltered and the ICD does not prevent insurgence of a malignant arrhythmia, especially during intensive exercise, although it will prevent SCD/CA (Class IIa/Level C).

Participation in competitive sports may be considered in the individual patient with cardiomyopathy and ICD, after careful consideration of the type of underlying cardiomyopathy (for instance, ARVC represents reason for contraindication). The deci- sion to participate in competitive sport should be made after full disclosure of the risks of sport participation with ICD, including the likelihood of appropriate/inappropriate shocks, leads failure, and the device-related trauma (Class IIb/Level C). With regard to type of sport, selected patients with cardiomyopathy and ICD may participate in all sport, with exception of sports with bodily contact, such as rugby, American football and martial arts in order to avoid damage to the generator box and the cardiac leads. ${ }^{52}$ Patients with cardiomyopathy and ICD should avoid sports where transient syncope from an arrhythmia or the jolt of a shock may cause serious injury or death, such as mountain climbing, surfing, motor racing, or deep-sea diving. ${ }^{52,53}$

\section{LEISURE-TIME PHYSICAL ACTIVITY IN PATIENTS WITH CARDIOMYOPATHY}

Exercise prescription in all individuals with cardiomyopathy is appropriate, except some exceptions (some patients with ICD, see section 6)..$^{53-55}$ It should be individualized, balancing the clinical status of the patient with the type, intensity and frequency of the physical and/or sport activity being considered. Exercise prescription should be based on performed exercise testing and complete cardiac evaluation, aiming for a submaximal, well-tolerated level of exercise intensity.

Patients should be fully informed about disease, its clinical presentation and variety of symptoms that may occur in association with exercise. Exercise should be started with a warm-up period and a cool-down period at the end of the session. Exercise programmes with progressive increase in intensity should be closely monitored by the physician (ideally in contact with the coach). Exercising should be avoided in adverse environmental conditions without prior acclimatization. Patients with cardiomyopathies should be encouraged to exercise in environments equipped with an automatic defibrillator and personnel trained in its use. ${ }^{53-55}$

\section{CONCLUSION}

The diagnosis of cardiomyopathy is based on complete cardiac evaluation with detailed personal and family history, 12-lead ECG, echocardiogram, CMRI, stress-testing as well as genetic testing and counseling at some subjects. The differentiation between the physiological adaptation to exercise and cardiomyopathy is of the mutual importance. Participation in intensive exercise programmes and competitive sport should be considered on an individual basis, after evaluation of the disease characteristics and risk determinants. Exercise prescription in all individuals with cardiomyopathy is appropriate, except some exceptions (ie. after implanted ICD). 


\section{LITERATURE}

1. Pelliccia A, Solberg EE, Papadakis M, et al. Recommendations for participation in competitive and leisure time sport in athletes with cardiomyopathies, myocarditis, and pericarditis: position statement of the Sport Cardiology Section of the European Association of Preventive Cardiology (EAPC). Eur Heart J. 2019;40(1):19-33. 2. Pelliccia A, Caselli S, Sharma S, et al; Internal reviewers for EAPC and EACVI. European Association of Preventive Cardiology (EAPC) and European Association of Cardiovascular Imaging (EACVI) joint position statement: recommendations for the indication and interpretation of cardiovascular imaging in the evaluation of the athlete's heart. Eur Heart J 2018;39:1949-1969.

3. Maron BJ, Doerer JJ, Haas TS, Tierney DM, Mueller FO. Sudden deaths in young competitive athletes: analysis of 1866 deaths in the United States, 1980-2006. Circulation 2009;119:1085-1092.

4. Harmon KG, Asif IM, Maleszewski JJ, Owens DS, Prutkin JM, Salerno JC, et al. Incidence, cause, and comparative frequency of sudden cardiac death in National Collegiate Athletic Association athletes: a decade in review. Circulation 2015;132:10-19.

5. Finocchiaro G, Papadakis M, Robertus JL, et al. Etiology of sudden death in sports: insights from a United Kingdom regional registry. J Am Coll Cardiol 2016;67:2108-2115.

6. Elliott PM, Anastasakis A, Borger MA, et al. 2014 ESC Guidelines on diagnosis and management of hypertrophic cardiomyopathy: the Task Force for the Diagnosis and Management of Hypertrophic Cardiomyopathy of the European Society of Cardiology (ESC). Eur Heart J 2015;35:7-79.

7. Gersh BJ, Maron BJ, Bonow RO, et al.; American College of Cardiology Foundation/American Heart Association Task Force on Practice Guidelines; American Association for Thoracic Surgery; American Society of Echocardiography; American Society of Nuclear Cardiology; Heart Failure Society of America; Heart Rhythm Society; Society for Cardiovascular Angiography and Interventions; Society of Thoracic Surgeons. 2011 ACCF/AHA guideline for the diagnosis and treatment of hypertrophic cardiomyopathy: a report of the American College of Cardiology Foundation/American Heart Association Task Force on Practice Guidelines. Circulation 2011;124:e783-e831.

8. Papadakis M, Carre F, Kervio G, et al. The prevalence, distribution, and clinical outcomes of electrocardiographic repolarization patterns in male athletes of African/Afro-Caribbean origin. Eur Heart J 2011;32:2304-2313.

9. Sheikh N, Papadakis M, Schnell F, et al. Clinical profile of athletes with hypertrophic cardiomyopathy. Circ Cardiovasc Imaging 2015;8:e003454.

10. Calore C, Zorzi A, Corrado D. Clinical meaning of isolated increase of QRS voltages in hypertrophic cardiomyopathy versus athlete's heart. J Electrocardiol 2015;48:373-379.

11. Pelliccia A, Maron BJ, Spataro A, Proschan MA, Spirito P. The upper limit of physiologic cardiac hypertrophy in highly trained elite athletes. N Engl J Med 1991;324:295-301.

12. Caselli S, Maron MS, Urbano-Moral JA, Pandian NG, Maron BJ, Pelliccia A. Differentiating left ventricular hypertrophy in athletes from that in patients with hypertrophic cardiomyopathy. Am J Cardiol 2014;114:1383-1389.

13. Finocchiaro G, Dhutia H, D'Silva A, et al. Role of Doppler diastolic parameters in differentiating physiological left ventricular hypertrophy from hypertrophic cardiomyopathy. J Am Soc Echocardiogr 2018;31:606-613.

14. Maron BJ, Pelliccia A, Spataro A, Granata M. Reduction in left ventricular wall thickness after deconditioning in highly trained Olympic athletes. Br Heart J 1993;69:125-128.

15. Rickers C, Wilke NM, Jerosch-Herold M, et al. Utility of cardiac magnetic resonance imaging in the diagnosis of hypertrophic cardiomyopathy. Circulation 2005;112:855-861.

16. Maron MS, Appelbaum E, Harrigan CJ, et al. Clinical profile and significance of delayed enhancement in hypertrophic cardiomyopathy. Circ Heart Fail 2008;1:184-191.

17. Sharma S, Elliott PM, Whyte G, et al. Utility of metabolic exercise testing in distinguishing hypertrophic cardiomyopathy from physiologic left ventricular hypertrophy in athletes. J Am Coll Cardiol 2000;36:864-870.

18. Sheikh N, Papadakis M, Wilson M, et al. Diagnostic yield of genetic testing in young athletes with $\mathrm{T}$-wave inversion. Circulation 2018;138:1184-1194.

19. Maron BJ, Udelson JE, Bonow RO, et al. Eligibility and disqualification recommendations for competitive athletes with cardiovascular abnormalities: task force 3: hypertrophic cardiomyopathy, arrhythmogenic right ventricular cardiomyopathy and other cardiomyopathies, and myocarditis: a scientific statement from the American Heart Association and American College of Cardiology. Circulation 2015;132:e273-e280. 20. Pinto YM, Elliott PM, Arbustini E, et al. Proposal for a revised definition of dilated cardiomyopathy, hypokinetic non-dilated cardiomyopathy, and its implications for clinical practice: a position statement of the ESC working group on myocardial and pericardial diseases. Eur Heart J 2016;37:1850-1858.

21. Rapezzi C, Arbustini E, Caforio AL, et al. Diagnostic work-up in cardiomyopathies: bridging the gap between clinical phenotypes and final diagnosis. A position statement from the ESC Working Group on Myocardial and Pericardial Diseases. Eur Heart J 2013;34: 1448-1458. 22. Gavazzi A, De Maria R, Renosto G, et al. The spectrum of left ventricular size in dilated cardiomyopathy: clinical correlates and prognostic implications. SPIC (Italian Multicenter Cardiomyopathy Study) Group. Am Heart J 1993;125:410-422.

23. Pelliccia A, Culasso F, Di Paolo FM, Maron BJ. Physiologic left ventricular cavity dilatation in elite athletes. Ann Intern Med 1999;130:2331.

24. Finocchiaro G, Dhutia H, D'Silva A, et al. Effect of sex and sporting discipline on LV adaptation to exercise. JACC Cardiovasc Imaging 2017;10:965-972.

25. Abergel E, Chatellier G, Hagege AA, Oblak A, Linhart A, Ducardonnet A, et al. Serial left ventricular adaptations in world-class professional cyclists: implications for disease screening and follow-up. J Am Coll Cardiol 2004;44: 144-149.

26. Millar L, Fernandez G, Dhutia H, al. Exercise echocardiography has 
a high sensitivity and specificity in differentiating athlete's heart from dilated cardiomyopathy. Circulation 2016;134:A15662.

27. Claessen G, Schnell F, Bogaert J, et al. Exercise cardiac magnetic resonance to differentiate athlete's heart from structural heart disease. Eur Heart J Cardiovasc Imaging 2018;19:1062-1070.

28. Gulati A, Jabbour A, Ismail TF, et al. Association of fibrosis with mortality and sudden cardiac death in patients with nonischemic dilated cardiomyopathy. JAMA 2013;309:896-908.

29. Halliday BP, Gulati A, Ali A, et al. Association between midwall late gadolinium enhancement and sudden cardiac death in patients with dilated cardiomyopathy and mild and moderate left ventricular systolic dysfunction. Circulation 2017;135:2106-2115.

30. Spezzacatene A, Sinagra G, Merlo M, et al; Familial Cardiomyopathy Registry. Arrhythmogenic phenotype in dilated cardiomyopathy: natural history and predictors of life-threatening arrhythmias. J Am Heart Assoc 2015;4:e002149.

31. van Rijsingen IA, Arbustini E, Elliott PM, et al. Risk factors for malignant ventricular arrhythmias in lamin a/c mutation carriers a European cohort study. J Am Coll Cardiol 2012;59:493-500. 32. Towbin JA, Lorts A, Jefferies JL. Left ventricular non-compaction cardiomyopathy. Lancet 2015;386:813-825.

33. Steffel J, Kobza R, Oechslin E, Jenni R, Duru F. Electrocardiographic characteristics at initial diagnosis in patients with isolated left ventricular noncompaction. Am J Cardiol 2009;104:984-989.

34. Jenni R, Oechslin E, Schneider J, Attenhofer Jost C, Kaufmann PA. Echocardiographic and pathoanatomical characteristics of isolated left ventricular non-compaction: a step towards classification as a distinct cardiomyopathy. Heart 2001;86:666-671.

35. Chin TK, Perloff JK, Williams RG, Jue K, Mohrmann R. Isolated noncompaction of left ventricular myocardium. A study of eight cases. Circulation 1990;82:507-513.

36. Gati S, Chandra N, Bennett RL, et al. Increased left ventricular trabeculation in highly trained athletes: do we need more stringent criteria for the diagnosis of left ventricular non-compaction in athletes? Heart 2013;99:401-408.

37. Gati S, Papadakis M, Papamichael ND, et al. Reversible de novo left ventricular trabeculations in pregnant women: implications for the diagnosis of left ventricular noncompaction in low-risk populations. Circulation 2014;130:475-483.

38. Caselli S, Attenhofer Jost CH, Jenni R, Pelliccia A. Left ventricular noncompaction diagnosis and management relevant to pre-participation screening of athletes. Am J Cardiol 2015;116:801-808.

39. Caselli S, Ferreira D, Kanawati E, et al. Prominent left ventricular trabeculations in competitive athletes: a proposal for risk stratification and management. Int J Cardiol 2016;223:590-595.

40. Petersen SE, Selvanayagam JB, Wiesmann F, et al. Left ventricular non-compaction: insights from cardiovascular magnetic resonance imaging. J Am Coll Cardiol 2005;46:101-105.

41. Zemrak F, Ahlman MA, Captur G, et al. The relationship of left ventricular trabeculation to ventricular function and structure over a 9.5-year follow-up: the MESA study. J Am Coll Cardiol 2014;64:1971-
1980.

42. Corrado D, Link MS, Calkins HN. Arrhythmogenic right ventricular cardiomyopathy. N Engl J Med 2017;376:61-72.

43. Thiene G, Nava A, Corrado D, Rossi L, Pennelli N. Right ventricular cardiomyopathy and sudden death in young people. N Engl J Med 1988;318:129-133.

44. Bagnall RD, Weintraub RG, Ingles J, et al. A prospective study of sudden cardiac death among children and young adults. N Engl J Med 2016;374:2441-2452.

45. Nasir K, Bomma C, Tandri H, et al. Electrocardiographic features of arrhythmogenic right ventricular dysplasia/cardiomyopathy according to disease severity: a need to broaden diagnostic criteria. Circulation 2004;110:1527-1534

46. Bauce B, Frigo G, Benini G, et al. Differences and similarities between arrhythmogenic right ventricular cardiomyopathy and athlete's heart adaptations. Br J

Sports Med 2010;44:148-154.

47. Perazzolo Marra M, Rizzo S, et al. Arrhythmogenic right ventricular cardiomyopathy. Contribution of cardiac magnetic resonance imaging to the diagnosis. Herz 2015;40:600-606.

48. Zaidi A, Ghani S, Sharma R, et al. Physiological right ventricular adaptation in elite athletes of African and Afro-Caribbean origin. Circulation 2013;127:1783-1792.

49. D’Ascenzi F, Pisicchio C, Caselli S, Di Paolo FM, Spataro A, Pelliccia A. RV remodeling in olympic athletes. JACC Cardiovasc Imaging 2017;10:385-393.

50. Marcus FI, McKenna WJ, Sherrill D, et al. Diagnosis of arrhythmogenic right ventricular cardiomyopathy/dysplasia: proposed modification of the task force criteria. Circulation 2010;121:1533-1541.

51. Calkins H, Corrado D, Marcus F. Risk stratification in arrhythmogenic right ventricular cardiomyopathy. Circulation 2017;136:20682082.

52. Heidbuchel H, Carre' F. Exercise and competitive sports in patients with an implantable cardioverter-defibrillator. Eur Heart J 2014;35:3097-3102.

53. Heidbuchel H, Corrado D, Biffi A, et al. Recommendations for participation in leisure-time physical activity and competitive sports of patients with arrhythmias and potentially arrhythmogenic conditions Part II: ventricular arrhythmias, channelopathies and implantable defibrillators. Eur J Cardiovasc Prev Rehabil 2006;13:676-686.

54. Maron BJ, Chaitman BR, Ackerman MJ, et al; Working Groups of the American Heart Association Committee on Exercise, Cardiac Rehabilitation, and Prevention; Councils on Clinical Cardiology and Cardiovascular Disease in the Young. Recommendations for physical activity and recreational sports participation for young patients with genetic cardiovascular diseases. Circulation 2004;109:2807-2816. 55. Pelliccia A, Quattrini F. Leisure-time physical activity and sport participation in patients with Cardiomyopathies. Card Electrophysiol Clin 2013;5:65-72. 
Review Article 